\section{Re: The Emergence of Primary Care in Latin America: Reflections from the Field}

To the Editor: As a physician who was trained and is licensed in the United States and is also licensed in El Salvador and has practiced in mission medicine in rural El Salvador for 20 years, I enjoyed Dr. Ventres's ${ }^{1}$ perspective on primary care in Central America. I concur with that author's observation that El Salvador does a fine job of providing community-level primary health care. Community health care promoters are providing outstanding care related to universal vaccinations, prenatal health care, environmental interventions for outbreaks of dengue fever, and hospital referrals for emergencies. Being personally acquainted with some of these promoters, I also see the unfortunate side of the efforts to improve health care outcomes: these promoters, themselves generally from impoverished communities, are frequently threatened and sometimes penalized for negative outcomes beyond their control. These rural promoters perceive themselves as being virtually voiceless and powerless in a system where the lowest tier of workforce may be easily replaced by others eager for work.

However, for the many impoverished people who will die of acute and chronic disease if they are only vaccinated and given prenatal care, El Salvador is providing inadequate health care. Our clinic is barraged with patients who left the (free) public health care system because there is no metformin available for diabetes, who continue suffering from a wheezy cough despite having (inappropriately) received amoxicillin, and whose cancers are misdiagnosed and undertreated until treatment is no longer an option. Dr. Ventres teaches in San Salvador; I understand why he doesn't experience this daily aspect of the grave limitations of the health care system. At the time when El Salvador's care of acute/chronic diseases matches the wisdom and thoroughness of their prevention of diseases, we will have a model for the world.

Jana L. Nisly, MD

Amish Mennonite Aid, Santa Ana, El Salvador erclinicjn@gmail.com

\section{Reference}

1. Ventres WB. The emergence of primary care in Latin America: reflections from the field. J Am Board Fam Med 2013;26:183-6.

doi: 10.3122/jabfm.2013.05.130133

\section{Response: Re: The Emergence of Primary Care in Latin America: Reflections from the Field}

Dr. Nisly expresses frustrations about her daily work as a mission physician in El Salvador and notes several examples of how the health care sys- tem is failing there. She is absolutely correct in noting that the reality of health care in El Salvador is far from perfect. I suspect that pretty much the same could be said currently about any system in any place around the world.

That such frustrations and realities exist, however, should not blind us to the hope of building more rational systems of health care delivery. Efforts to develop community-based, locally accessible primary care services are worthy of support. Four years after the first peaceful democratic transfer of power in El Salvador's history, the current Ministry of Health is slowly making progress on its platform of reform. I applaud it for even trying.

More to the point for readers of the Fournal of the American Board of Family Medicine, every system of health care around the globe has weaknesses and strengths. Our greatest challenge as practitioners in the global community is to learn both from failures as well as successes-be they "theirs" or "ours"- and to acknowledge them honestly with measures of humility and respect. Above all else, that is the take home point from my article and this response.

William Ventres, MD, MA

Institute for Studies in History, Anthropology and Archeology, University of El Salvador San Salvador, El Salvador wventres@gmail.com doi: 10.3122/jabfm.2013.05.130193

\section{Re:Journal of the American Board of Family Medicine Issue on Communities of Solution}

To the Editor: We appreciated the Fournal of the American Board of Family Medicine issue (May/June 2013) dedicated to communities of solution (COSs) and believe that this topic enhances meaningful conversation around the role of health care institutions in improving individual and population health. Griswold et $\mathrm{al}^{1}$ highlighted key themes of COSs, such as crossing "jurisdictional boundaries" and community-based initiatives. The rest of the dedicated issue focused on specific examples of COSs related to these themes, including Ferrer et al's ${ }^{2}$ "advanced" multidisciplinary primary care and Garney et al's ${ }^{3}$ health resource centers. These examples are salient, 